Keywords: $M C U, A R P, I S D P$

Retention: Permanent

\title{
Results of Routine Strip Effluent Hold Tank and Decontaminated Salt Solution Hold Tank Samples from Modular Caustic-Side Solvent Extraction Unit during Macrobatch 3 Operations
}

T. B. Peters

S. D. Fink

July 2011

Savannah River National Laboratory Savannah River Nuclear Solutions

Aiken, SC 29808

Prepared for the U.S. Department of Energy under

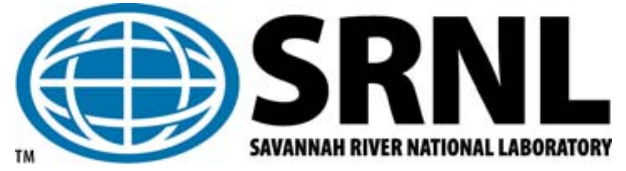
contract number DE-AC09-08SR22470. 
SRNL-STI-2011-00411

Revision 0

\section{DISCLAIMER}

This work was prepared under an agreement with and funded by the U.S. Government. Neither the U.S. Government or its employees, nor any of its contractors, subcontractors or their employees, makes any express or implied:

1. warranty or assumes any legal liability for the accuracy, completeness, or for the use or results of such use of any information, product, or process disclosed; or

2. representation that such use or results of such use would not infringe privately owned rights; or

3. endorsement or recommendation of any specifically identified commercial product, process, or service.

Any views and opinions of authors expressed in this work do not necessarily state or reflect those of the United States Government, or its contractors, or subcontractors.

\section{Printed in the United States of America}

Prepared for

U.S. Department of Energy 


\section{REVIEWS AND APPROVALS}

\section{AUTHORS:}

T. B. Peters, Author, SRNL/SASP

Date

TECHNICAL REVIEW:

C. A. Nash, Technical Reviewer, SRNL/ACP

Date

APPROVAL:

S. D. Fink, SRNL/SASP, Manager

Date

S. L. Marra, SRNL/E\&CPT Research Programs, Manager

Date

D. J. Martin, Manager, H Tank Farm Engineering

Date 


\section{EXECUTIVE SUMMARY}

Strip Effluent Hold Tank (SEHT) and Decontaminated Salt Solution Hold Tank (DSSHT) samples from several of the "microbatches" of Integrated Salt Disposition Project (ISDP) Salt Batch ("Macrobatch") 3 have been analyzed for ${ }^{238} \mathrm{Pu},{ }^{90} \mathrm{Sr},{ }^{137} \mathrm{Cs}$, and by Inductively Coupled Plasma Emission Spectroscopy (ICPES). The results indicate good decontamination performance within process design expectations. While the data set is sparse, the results of this set and the previous set of results for Macrobatch 3 samples indicate generally consistent operations.

However, the Decontamination Factors for plutonium and strontium removal have declined in Macrobatch 3, compared to Macrobatch 2. This may be due to the differences in the Pu concentration or the bulk chemical concentrations in the feed material. SRNL is considering the possible reasons for this decline.

The DSSHT samples show continued presence of titanium, likely from leaching of the monosodium titanate in ARP. 


\title{
LIST OF ABBREVIATIONS
}

\author{
ARP - Actinide Removal Process \\ DSS - Decontaminated Salt Solution \\ DSSHT - Decontaminated Salt Solution Hold Tank \\ ICPES - inductively-coupled plasma emission spectroscopy \\ MCU - Modular Caustic-Side Solvent Extraction Unit \\ MST - monosodium titanate \\ SE - Strip Effluent \\ SEHT - Strip Effluent Hold Tank \\ SRNL - Savannah River National Laboratory \\ SSRT - Salt Solution Receipt Tank
}




\subsection{Introduction}

During operation of the ISDP, quantities of salt waste are processed through the Actinide Removal Process (ARP) and MCU in batches of $~ 3800$ gallons. Monosodium titanate (MST) is used in ARP to adsorb actinides and strontium from the salt waste and the waste slurry is then filtered prior to sending the clarified salt solution to MCU. The MCU uses solvent extraction technology to extract cesium from salt waste and concentrate cesium in an acidic aqueous stream (Strip Effluent - SE), leaving a decontaminated caustic salt aqueous stream (Decontaminated Salt Solution - DSS). Sampling occurs in the Decontaminated Salt Solution Hold Tank (DSSHT) and Strip Effluent Hold Tank (SEHT) in the MCU process. The MCU sample plan ${ }^{1}$ requires that batches be sampled and analyzed for plutonium and strontium content by Savannah River National Lab (SRNL) to determine MST effectiveness. The cesium measurement is used to monitor cesium removal effectiveness and the inductively coupled plasma emission spectroscopy (ICPES) is used to monitor inorganic carryover.

A previous report provided the results of several sets of microbatch results from Macrobatch 3 operations. ${ }^{2}$

Since that report, SRNL received subsequent SEHT and DSSHT samples from Macrobatch 3. Not all microbatch samples were delivered to SRNL for analysis. Results for previously reported samples are reported in this document and compared to current trends.

\subsection{Experimental Procedure}

The samples were contained in 10-mL P-nut vials. SEHT samples were delivered in doorstops for shielding purposes, while the DSSHT samples were delivered in thief holders. Samples were removed from the holders and sent to Analytical Development. The DSSHT samples were not diluted or filtered. Some of the SEHT samples were diluted where necessary to reduce personnel exposure. We measured the $\mathrm{pH}$ of all the SE samples using $\mathrm{pH}$ strips.

\subsection{Results and Discussion}

The radiochemical results from the DSSHT and SEHT analyses are listed in Table 1. Entries in the "Source Material" column that are shaded blue are from a report ${ }^{3}$ that calculated the values from knowing the concentrations and blend volumes; other values are from direct measurement. ${ }^{4}$ 
Table 1. Radiochemical Results for the DSSHT and SEHT Results

\begin{tabular}{|c|c|c|c|c|c|}
\hline Microbatch & Sample ID & Sample Date & ${ }^{238} \mathbf{P u}(\mathbf{d p m} / \mathbf{m L})$ & ${ }^{\mathbf{9 0}}$ Sr (dpm/mL) & ${ }^{\mathbf{1 3 7}} \mathbf{C s}(\mathbf{d p m} / \mathbf{m L})$ \\
\hline \multicolumn{7}{|c|}{ DSSHT } \\
\hline 115 & MCU-11-133 & $2 / 23 / 2011$ & $1.30 \mathrm{E}+03(5.00 \%)$ & $2.17 \mathrm{E}+03(9.96 \%)$ & $6.41 \mathrm{E}+05(5.00 \%)$ \\
\hline 137 & MCU-11-247 & $3 / 24 / 2011$ & $3.20 \mathrm{E}+03(5.12 \%)$ & $3.24 \mathrm{E}+03(8.65 \%)$ & $1.05 \mathrm{E}+06(5.00 \%)$ \\
\hline 153 & MCU-11-361 & $4 / 27 / 2011$ & $3.29 \mathrm{E}+03(5.12 \%)$ & $3.25 \mathrm{E}+03(9.09 \%)$ & $9.11 \mathrm{E}+05(5.00 \%)$ \\
\hline 79 & MCU-11-37 & $1 / 12 / 2011$ & $<1.53 \mathrm{E}+01$ & $<7.98 \mathrm{E}+02$ & $1.93 \mathrm{E}+09(5.00 \%)$ \\
\hline 92 & MCU-11-137 & $3 / 7 / 2011$ & $<8.95 \mathrm{E}+00$ & $<7.06 \mathrm{E}+02$ & $1.94 \mathrm{E}+09(5.00 \%)$ \\
\hline 107 & MCU-11-251 & $3 / 24 / 2011$ & $<8.70 \mathrm{E}+00$ & $2.23 \mathrm{E}+03(17.0 \%)$ & $2.05 \mathrm{E}+09(5.00 \%)$ \\
\hline 121 & MCU-11-362 & $4 / 27 / 2011$ & $<7.38 \mathrm{E}+00$ & $<7.04 \mathrm{E}+02$ & $1.99 \mathrm{E}+09(5.00 \%)$ \\
\hline $\begin{array}{l}\text { Feed Waste } \\
\text { (Tank 49H) }\end{array}$ & & $2.78 \mathrm{E}+04$ & $3.57 \mathrm{E}+05$ & $1.45 \mathrm{E}+08(5.00 \%)$ \\
\hline
\end{tabular}

The microbatch 107 SEHT sample result for ${ }^{90} \mathrm{Sr}$ is noticeably different from previous samples in this Macrobatch. Considering that the other results for this sample are within expectations, the sample as a whole is not compromised. The ${ }^{90} \mathrm{Sr}$ result appears to be an outlier, but not indicative of a process upset. The lack of a high ${ }^{238} \mathrm{Pu}$ result, or a high titanium result (see Table 6) for the same sample indicates no bulk breakthrough of MST solids. All the SE samples were measured to have a pH of 3, which is expected. 
While we do not have many data points for this Macrobatch, what we do have shows a similar pattern to the comparable samples from Macrobatch 2 operations. Figure 1 shows all of the Macrobatch 3 DSSHT ${ }^{238} \mathrm{Pu}$ samples we have analyzed to date, overlaid against the comparable Macrobatch 2 samples. Figure 2 shows the same for ${ }^{90} \mathrm{Sr}$. Figure 3 shows the similar ${ }^{137} \mathrm{Cs}$ data, but also includes the SEHT samples.

Figure 1. ${ }^{238} \mathrm{Pu}$ Data for Selected Macrobatch 2 and 3 DSSHT Samples

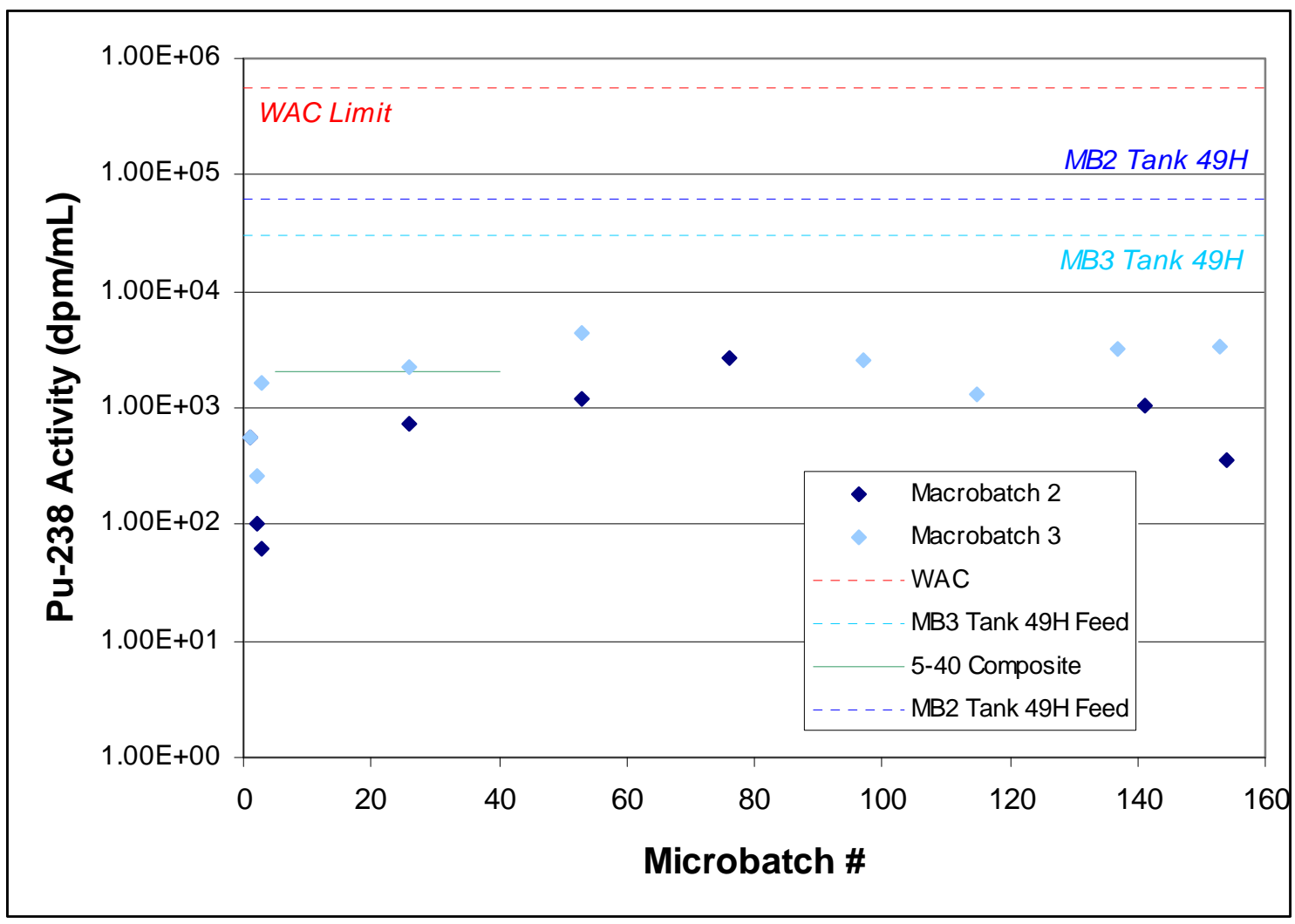

While the graph of the Pu data can show the overall trend, it is also important to consider the decontamination factors (DF). While rigorous determination of the DF requires considerations of the flow rates as recorded in the facility, we present the data to give a general comparison between Macrobatch 2 and 3. 
Table 2. ${ }^{238}$ Pu Decontamination Factors for Selected Macrobatch 2 and 3 Samples

\begin{tabular}{|c|c|c|}
\hline \multirow{2}{*}{ Microbatch Sample \# } & \multicolumn{2}{|c|}{${ }^{238} \mathrm{Pu}$ DF Value } \\
\cline { 2 - 3 } & Macrobatch 2 & Macrobatch 3 \\
\hline 1 & 113 & 50.5 \\
\hline 2 & 606 & 106 \\
\hline 3 & 1010 & 17.1 \\
\hline 26 & 83.6 & 12.5 \\
\hline 53 & 52.8 & 6.41 \\
\hline 76 & 23.4 & no sample \\
\hline 97 & no sample & 10.7 \\
\hline 115 & no sample & 21.4 \\
\hline 137 & no sample & 8.69 \\
\hline 141 & 60.0 & no sample \\
\hline 153 & no sample & 8.45 \\
\hline 154 & 175 & no sample \\
\hline
\end{tabular}

A consideration of microbatch samples shows a continued decline in the Pu DFs. This may be due to the differences in the Pu concentration or the bulk chemical concentrations in the feed material.

A previous study investigated the concentration effects of the six most common anions in salt solutions $\left(\mathrm{NO}_{3}{ }^{-}, \mathrm{OH}^{-}, \mathrm{NO}_{2}{ }^{-}, \mathrm{Al}(\mathrm{OH})_{4}{ }^{-}, \mathrm{CO}_{3}{ }^{2-}\right.$ and $\left.\mathrm{SO}_{4}{ }^{2-}\right) .{ }^{5}$ The most appropriate predictive equation (7 day Pu DFs, equation 4) indicates that increasing $\mathrm{NO}_{3}{ }^{-}$, and $\mathrm{SO}_{4}{ }^{2-}$ concentrations increase DF, while concentration increases in the other anions decrease the Pu DFs. Using the analyses of Macrobatch 2 and Macrobatch 3 as inputs to this predictive equation provides that Macrobatch 2 should have better Pu removal, by a factor of $\sim 2$. We are outside the range of several of the variables, such as nitrate concentration, time, scale of operations, and quantity of MST. Therefore, this result should be considered tentative, but we consider the relative comparison to be appropriate. 
Figure 2. ${ }^{90}$ Sr Data for Selected Macrobatch 2 and 3 DSSHT Samples

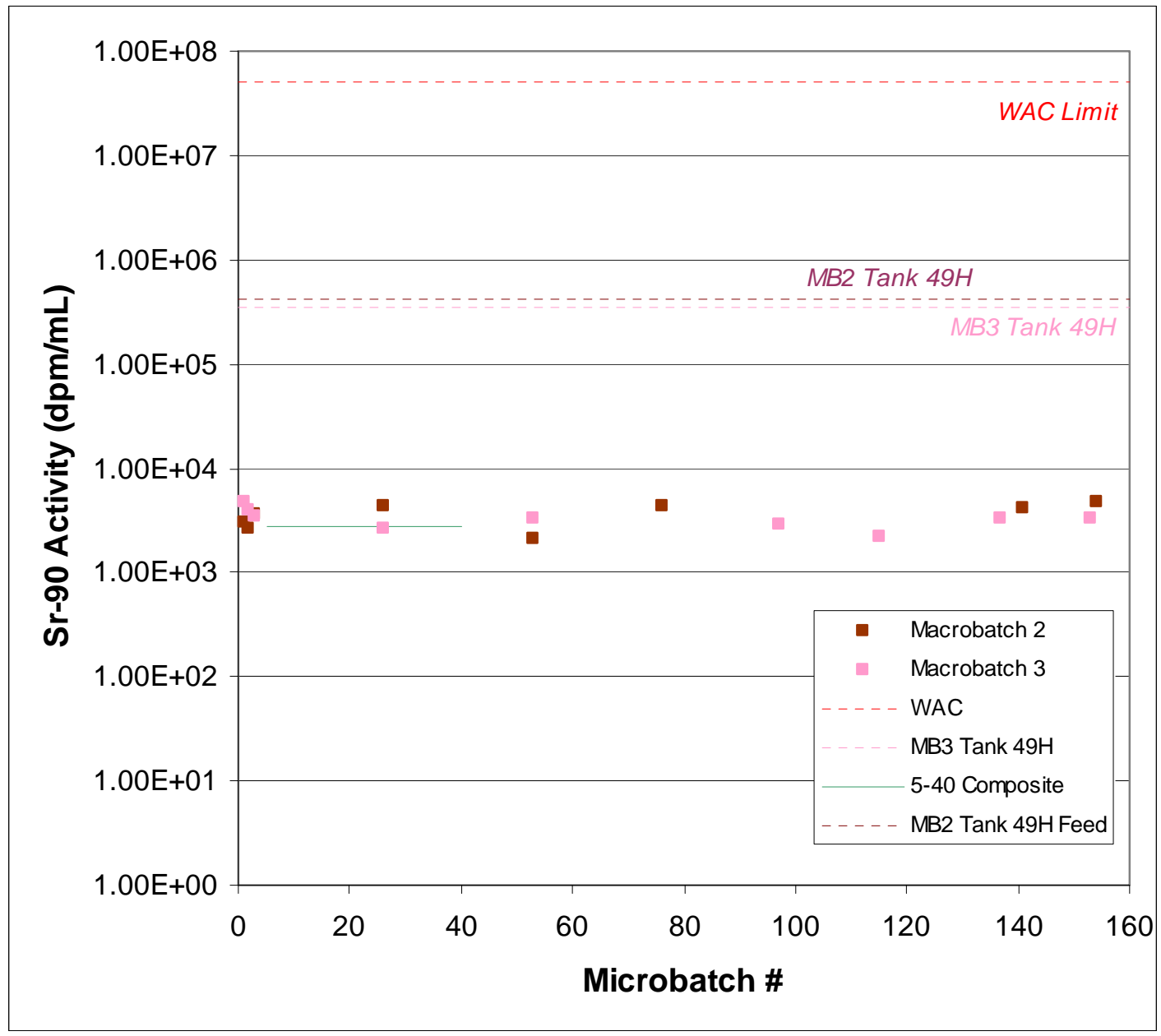

Table 3. ${ }^{90}$ Sr Decontamination Factors for Selected Macrobatch 2 and 3 Samples

\begin{tabular}{|c|c|c|}
\hline \multirow{2}{*}{ Microbatch Sample \# } & \multicolumn{2}{|c|}{${ }^{90}$ Sr DF Value } \\
\cline { 2 - 3 } & Macrobatch 2 & Macrobatch 3 \\
\hline 1 & 142 & 75.0 \\
\hline 2 & 158 & 90.4 \\
\hline 3 & 119 & 103 \\
\hline 26 & 96.4 & 134 \\
\hline 53 & 202 & 110 \\
\hline 76 & 99.8 & no sample \\
\hline 97 & no sample & 124 \\
\hline 115 & no sample & 110 \\
\hline 137 & no sample & 115 \\
\hline 141 & 100 & no sample \\
\hline 153 & no sample & 118 \\
\hline 154 & 91.0 & no sample \\
\hline
\end{tabular}


The ${ }^{90}$ Sr values also show approximately the same behavior between Macrobatch 2 and Macrobatch 3. The average Sr DF over the Macrobatch 2 samples is 126, while the average for the Macrobatch 3 samples is 111. If we examine the predicted DFs using the same study as we used with plutonium, ${ }^{5}$ we predict a DF of 137 for Macrobatch 2 and 195 for Macrobatch 3. While this does not match the trend in our data, at least we have no indication that bulk chemical properties are the cause of the slight strontium DF decline.

The ${ }^{137}$ Cs data for this macrobatch matches the previous macrobatch samples fairly well. However, a detailed comparison is difficult due to the lack of ${ }^{137} \mathrm{Cs}$ samples is the previous macrobatch.

\section{Figure 3. ${ }^{137}$ Cs Data for Selected Macrobatch 2 and 3 Samples}

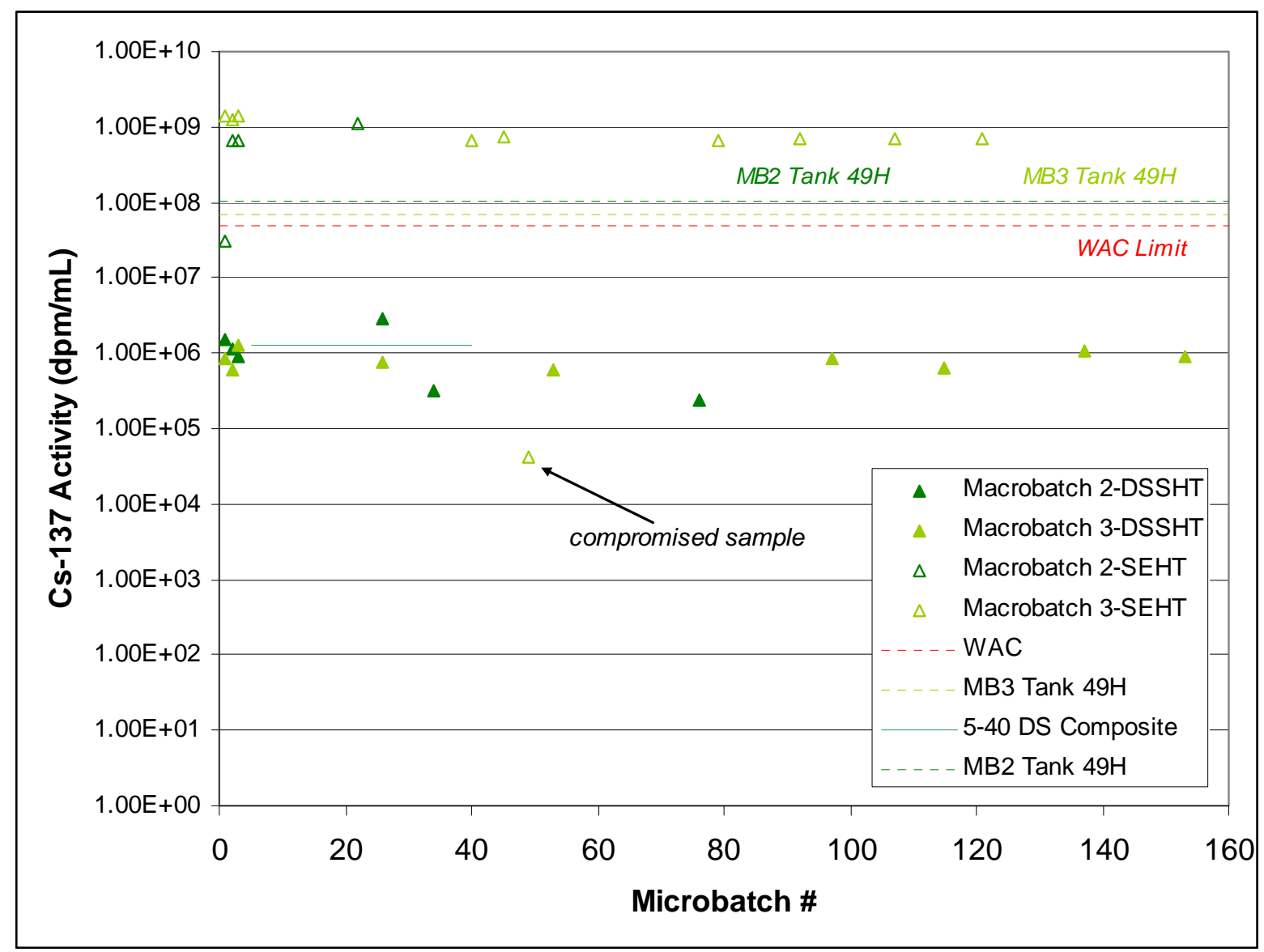




\section{Table 4. ${ }^{137}$ Cs Decontamination Factors for Selected Macrobatch 2 and 3 Samples}

\begin{tabular}{|c|c|c|}
\hline \multirow{2}{*}{ Microbatch Sample \# } & \multicolumn{2}{|c|}{${ }^{137}$ Cs DF Value } \\
\cline { 2 - 3 } & Macrobatch 2 & Macrobatch 3 \\
\hline 1 & 68.2 & 168 \\
\hline 2 & 92.1 & 248 \\
\hline 3 & 114 & 117 \\
\hline 26 & 37.0 & 195 \\
\hline 53 & 334 & 240 \\
\hline 76 & 451 & 170 \\
\hline 115 & no sample & 226 \\
\hline 137 & no sample & 138 \\
\hline 153 & no sample & 159 \\
\hline
\end{tabular}

While there is a great deal of variation between the microbatch samples within their own macrobatch, as well as between macrobatches, the averages of all samples within a macrobatch is the same (Macrobatch 2 DF average = 183 vs. 177 for Macrobatch 3).

The ICPES results for the DSSHT samples are listed in Table 5, and the ICPES results for the SEHT samples are listed in Table 6. The "source material" column is the analyzed concentration of the analyte in Tank $49 \mathrm{H}$. Note that material from Tank $49 \mathrm{H}$ undergoes a $\sim 20 \mathrm{vol} \%$ dilution from ARP and MCU. ${ }^{\Upsilon}$ Therefore, direct comparisons between the source material and the DSSHT sample results should take this into account. We note that a comparison of several of the more concentrated analytes ( $\mathrm{Al}, \mathrm{B}, \mathrm{Cr}, \mathrm{K}, \mathrm{Li}$, $\mathrm{Na}, \mathrm{P}$, and S) gives an average dilution factor of $\sim 27 \%$. This would suggest additional dilution is happening at ARP or MCU, possibly from high scrub acid flow, or rainwater addition from the sumps.

The DSSHT samples give the expected results - a dilution compared to the source material in the analytes. This is most easily see in those elements that should remain unaffected by the ARP and MCU chemistry - Al, B, Cr, S (from sulfate), P (from phosphate), etc. The notable exception to this is the silicon values which are higher than the feed material. The microbatch samples from the previous report ${ }^{2}$ also show a trend of high silicon values. These higher silicon values may be due to slow dissolution of the solids observed during prior replacement of the pump in the SSRT. ${ }^{6}$ It is unlikely that the higher than expected silicon is from sample handling or preparation.

\footnotetext{
${ }^{\Upsilon}$ Each 3600 gallon batch of material is mixed with 210 gallons of MST slurry, and is then combined with 1 volume of scrub acid for each 7.5 volumes of salt solution (this is double the nominal rate of scrub acid). This dilutes each 3600 gallons to 4318 gallons, or $20 \mathrm{vol} \%$ increase in volume.
} 
Table 5. ICPES Results for the DSSHT Samples

\begin{tabular}{|c|c|c|c|c|}
\hline Analyte & Microbatch 115 & Microbatch 137 & Microbatch 153 & Source Material (mg/L) \\
\hline $\mathrm{Ag}$ & $<1.46$ & $<1.46$ & $<1.46$ & $<2.14$ \\
\hline $\mathrm{Al}$ & 4260 & 4520 & 4530 & 5290 \\
\hline B & 71.2 & 72.2 & 67.6 & 82.6 \\
\hline $\mathrm{Ba}$ & 2.68 & 2.72 & 1.49 & $<0.59$ \\
\hline $\mathrm{Be}$ & $<0.08$ & $<0.08$ & $<0.08$ & $<0.7$ \\
\hline $\mathrm{Ca}$ & 1.63 & 1.55 & 1.06 & 2.27 \\
\hline $\mathrm{Cd}$ & $<0.7$ & $<0.7$ & $<0.7$ & 1.17 \\
\hline $\mathrm{Ce}$ & $<6.03$ & $<6.03$ & $<6.03$ & $<6.6$ \\
\hline $\mathrm{Cr}$ & 59.5 & 61.4 & 61.4 & 71.6 \\
\hline $\mathrm{Cu}$ & 1.07 & 1.26 & 1.15 & 1.68 \\
\hline $\mathrm{Fe}$ & 2.13 & 2.13 & 1.88 & 12.2 \\
\hline Gd & $<0.78$ & $<0.78$ & $<0.78$ & $<2.12$ \\
\hline $\mathrm{K}$ & 350 & 362 & 365 & 480 \\
\hline $\mathrm{La}$ & $<0.54$ & $<0.54$ & $<0.54$ & $<1$ \\
\hline $\mathrm{Li}$ & 18.4 & 18.8 & 18.5 & 25.6 \\
\hline $\mathrm{Mg}$ & $<0.15$ & 0.215 & $<0.15$ & $<0.25$ \\
\hline $\mathrm{Mn}$ & $<0.53$ & $<0.53$ & $<0.53$ & 0.88 \\
\hline Mo & 6.93 & 6.99 & 6.44 & 8.47 \\
\hline $\mathrm{Na}$ & 137000 & 139000 & 138000 & 157000 \\
\hline $\mathrm{Ni}$ & $<1.6$ & $<1.6$ & $<1.6$ & $<2.35$ \\
\hline $\mathrm{P}$ & 208 & 210 & 210 & 272 \\
\hline $\mathrm{Pb}$ & $<7.16$ & $<7.16$ & $<7.16$ & $<7.31$ \\
\hline $\mathrm{S}$ & 1920 & 1990 & 1970 & 2410 \\
\hline $\mathrm{Sb}$ & $<10.7$ & $<10.7$ & $<10.7$ & $<10.4$ \\
\hline $\mathrm{Si}$ & 317 & 259 & 249 & 168 \\
\hline Sn & $<5.61$ & $<5.61$ & $<5.61$ & $<4.29$ \\
\hline $\mathrm{Sr}$ & 0.09 & 0.065 & $<0.05$ & $<0.08$ \\
\hline $\mathrm{Ti}$ & $<0.38$ & 2.96 & 8.17 & $<0.17$ \\
\hline $\mathrm{U}$ & $<32.7$ & $<32.7$ & $<32.7$ & $<44.5$ \\
\hline $\mathrm{V}$ & $<0.47$ & $<0.47$ & $<0.47$ & $<0.52$ \\
\hline $\mathrm{Zn}$ & 21 & 8.53 & 10.5 & 6.5 \\
\hline $\mathrm{Zr}$ & $<0.25$ & $<0.25$ & $<0.25$ & $<0.89$ \\
\hline
\end{tabular}

The analytical uncertainty for the ICPES samples is $10 \%$. 
Table 6. ICPES Results for the SEHT Samples

\begin{tabular}{|c|c|c|c|c|}
\hline \multirow{2}{*}{ Analyte } & \multicolumn{4}{|c|}{ SEHT Sample Results (mg/L) } \\
\hline & Microbatch 79 & Microbatch 92 & Microbatch 107 & Microbatch 121 \\
\hline $\mathrm{Ag}$ & $<0.146$ & $<0.146$ & $<0.146$ & $<0.146$ \\
\hline $\mathrm{Al}$ & $<0.332$ & $<0.332$ & $<0.332$ & $<0.332$ \\
\hline $\mathrm{B}$ & $<0.202$ & $<0.202$ & $<0.202$ & $<0.202$ \\
\hline $\mathrm{Ba}$ & 0.154 & 0.043 & 0.043 & 0.035 \\
\hline $\mathrm{Be}$ & $<0.008$ & $<0.008$ & $<0.008$ & $<0.008$ \\
\hline $\mathrm{Ca}$ & 0.953 & 0.678 & 0.639 & 0.314 \\
\hline $\mathrm{Cd}$ & $<0.07$ & $<0.07$ & $<0.07$ & $<0.07$ \\
\hline $\mathrm{Ce}$ & $<0.603$ & $<0.603$ & $<0.603$ & $<0.603$ \\
\hline $\mathrm{Cr}$ & $<0.102$ & $<0.102$ & $<0.102$ & $<0.102$ \\
\hline $\mathrm{Cu}$ & 0.556 & 0.556 & 0.552 & 0.556 \\
\hline $\mathrm{Fe}$ & 0.087 & 0.389 & 0.209 & 0.344 \\
\hline Gd & $<0.078$ & $<0.078$ & $<0.078$ & $<0.078$ \\
\hline $\mathrm{K}$ & $<3.01$ & $<3.01$ & $<3.01$ & $<3.01$ \\
\hline $\mathrm{La}$ & $<0.054$ & $<0.054$ & $<0.054$ & $<0.054$ \\
\hline $\mathrm{Li}$ & $<0.146$ & $<0.146$ & $<0.146$ & $<0.146$ \\
\hline $\mathrm{Mg}$ & 0.217 & 0.181 & 0.142 & 0.0575 \\
\hline $\mathrm{Mn}$ & $<0.053$ & $<0.053$ & $<0.053$ & $<0.053$ \\
\hline Mo & $<0.268$ & $<0.268$ & $<0.268$ & $<0.268$ \\
\hline $\mathrm{Na}$ & 9.66 & 9.3 & 5.97 & 5.56 \\
\hline $\mathrm{Ni}$ & $<0.16$ & $<0.16$ & $<0.16$ & $<0.16$ \\
\hline $\mathrm{P}$ & $<1.64$ & $<1.64$ & $<1.64$ & $<1.64$ \\
\hline $\mathrm{Pb}$ & $<0.716$ & $<0.716$ & $<0.716$ & $<0.716$ \\
\hline$S$ & $<7.5$ & $<7.5$ & $<7.5$ & $<7.5$ \\
\hline $\mathrm{Sb}$ & $<1.07$ & $<1.07$ & $<1.07$ & $<1.07$ \\
\hline Si & $<0.439$ & $<0.439$ & $<0.439$ & $<0.439$ \\
\hline $\mathrm{Sn}$ & $<0.561$ & $<0.561$ & $<0.561$ & $<0.561$ \\
\hline $\mathrm{Sr}$ & $<0.005$ & $<0.005$ & $<0.005$ & $<0.005$ \\
\hline $\mathrm{Ti}$ & $<0.038$ & $<0.038$ & $<0.038$ & $<0.038$ \\
\hline $\mathrm{U}$ & $<3.27$ & $<3.27$ & $<3.27$ & $<3.27$ \\
\hline V & $<0.047$ & $<0.047$ & $<0.047$ & $<0.047$ \\
\hline $\mathrm{Zn}$ & 2.44 & 1.67 & 1.24 & 0.639 \\
\hline $\mathrm{Zr}$ & $<0.025$ & $<0.025$ & $<0.025$ & $<0.025$ \\
\hline
\end{tabular}

The analytical uncertainty for the ICPES samples is $10 \%$. 
The titanium results in the DSSHT samples are notable. In two cases, we have greater than detectable levels of $\mathrm{Ti}$ in the samples, where there is less-than detectable amounts in the feed material. This is important, as the only possible source of Ti is from the MST used at ARP. In fact, SRNL has found evidence of Ti-containing solids in the DSSHT coalescer and pre-filters. Testing in progress at SRNL has shown that Ti leaching from MST increases at higher free hydroxide concentration in the waste solution; this is suspected as a leading contributor to the Ti component in the MCU samples. The work on this subject is not complete and will be reported at a later date.

The SEHT samples follow the general trends observed for the previous sample results. ${ }^{2}$ For example, the sodium levels in all of the SEHT samples to date show the same approximate concentration. This is a good indication that the bulk chemistry has not changed, and also suggests that the aqueous carryover from the feed material into the solvent, and then back to the SE is not varying too greatly. While the previous report ${ }^{2}$ noted a high degree of variation in the iron and silicon results, we no longer see evidence of this in this set of samples.

\subsection{Conclusions}

The results from the current microbatch samples are similar to that from comparable samples in Macrobatch 2. However, the plutonium and strontium DFs in this set of samples continue to be less than comparable samples in Macrobatch 2. SRNL is looking into possible reasons for this disparity.

From a bulk chemical point of view, the ICPES results do not vary considerably between previous results and this Macrobatch. However, there are initial indications that the overall system dilution may be somewhat greater than theoretical ( 27\% vs. $20 \%$ ). ARP and MCU should check the aqueous inputs into their systems to make sure we are not out of specifications in such things as flush water (ARP) or scrub acid rate (MCU).

Finally, the titanium results in the DSSHT samples continue to indicate the presence of $\mathrm{Ti}$, when the feed material does not have detectable levels. This most likely indicates that leaching of Ti from MST has increased in ARP at the higher free hydroxide concentrations in the current feed. 


\subsection{References}

${ }^{1}$ M. W. Geeting, “Interim Salt Disposition Project (ISDP) Sample Plan”, U-ESR-H-00068, Revision 5, April 28, 2009.

${ }^{2}$ Peters, T. B., Fink, S. D., "Results of Routine Strip Effluent Hold Tank and Decontaminated Salt Solution Hold Tank Samples from Modular Caustic-Side Solvent Extraction Unit during Macrobatch 3 Operations” SRNL-STI-2011-00297, June 2011.

${ }^{3}$ S. E. Campbell, “Blend Evaluation for Tank 49H Feed for ISDP Salt Batch 3”, X-ESR-H-00209, March 16, 2010.

${ }^{4}$ T. B. Peters, S. D. Fink, "Results from ISDP3 Tank 49H Confirmatory Samples”, SRNL-STI-2010-00234, April 2010.

${ }^{5}$ M. J. Barnes, T. B. Edwards, D. T. Hobbs, K. M. Marshall, "Strontium and Actinide Removal Testing with Monosodium Titanate and Other Sorbents”, WSRC-TR-2001-00436, Rev.0, October 29, 2001.

${ }^{6}$ T. B. Peters, S. D. Fink, “Sample Results from Solids Isolated from the SSFT”, SRNL-STI-2011-00022, March 2011. 


\section{Distribution:}
E. J. Freed, 704-56H
D. J. Martin, 241-152H
M. W. Geeting, 241-152H
B. A. Gifford, 704-56H
S. P. McLeskey, 241-152H
B. A. Oard, 241-197H
R. E. Edwards, Jr., 773-67A
K. D. Harp, 766-H

S. L. Marra, 773-A

D. A. Crowley, 773-43A

M .J. Barnes, 773-A

C. C. Herman, 99-W

B. J. Giddings, 786-5A

F. M. Pennebaker, 773-42A

T.B. Peters, 773-42A

C. A. Nash, 773-42A

M. R. Poirier, 773-42A

F. F. Fondeur, 773-A

R. A. Pierce, 773-A

R. K. Leugemors, 992-5W

W. B. Brasel, 992-2W

C. Conner, Parsons

R. Lentsch, Parsons

P.C. Suggs, 704-S

P. R. Jackson, 703-46A 